\title{
Unravelling causality from correlations : revealing the impacts of endemic ectoparasites on a protected species (tuatara)
}

\author{
STEPHANIE S. GODFREY ${ }^{1 *}$, JENNIFER A. MOORE ${ }^{2}$, NICOLA J. NELSON ${ }^{2}$ and \\ C. MICHAEL BULL ${ }^{1}$ \\ ${ }^{1}$ School of Biological Sciences, Flinders University, Adelaide 5001, Australia \\ ${ }^{2}$ Allan Wilson Centre for Molecular Ecology and Evolution, School of Biological Sciences, Victoria University of Wellington, \\ New Zealand
}

(Received 10 May 2009; revised 15 Fuly 2009; accepted 25 July 2009; first published online 16 October 2009)

\begin{abstract}
SUMMARY
Understanding the impacts of endemic parasites on protected hosts is an essential element of conservation management. However, where manipulative experiments are unethical, causality cannot be inferred from observational correlative studies. Instead, we used an experimental structure to explore temporal associations between body condition of a protected reptile, the tuatara (Sphenodon punctatus) and infestation with ectoparasites (ticks and mites). We surveyed tuatara in a mark-recapture study on Stephens Island (New Zealand), which encompassed the pre-peak, peak and post-peak infestation periods for each ectoparasite. Tick loads during the peak infestation period were negatively related to body condition of tuatara. Body condition before the peak was not related to subsequent infestation rates; however, tick loads in the peak were negatively related to subsequent changes in body condition. Mite loads during the peak infestation period were not correlated with body condition of tuatara. Body condition before the peak had no effect on subsequent mite infestation rates, but mite loads of small males during the peak were negatively related to subsequent changes in body condition. Our results suggest that both ectoparasites reduce the body condition of tuatara, which has implications for the long-term conservation management of this host and its parasites.
\end{abstract}

Key words: body condition, host-parasite dynamics, ticks, trombiculid mites, conservation.

\section{INTRODUCTION}

Understanding the impacts of parasites in natural host-parasite systems is vital to conservation management (McCallum and Dobson, 1995). However, investigating the effects of parasites on threatened species poses an ethical problem. Experimental manipulation of parasite loads directly measures the impact of parasites on host fitness indicators, such as behaviour (Main and Bull, 2000; Hoodless et al. 2002; Fenner and Bull, 2008), body condition and reproductive success (Merino et al. 2000; Neuhaus, 2003; Tomas et al. 2007). However, for protected species, where legal or ethical considerations prevent any potentially harmful experiments, increasing parasite loads is rarely possible. Similarly, treating hosts with parasiticides to reduce parasite loads can cause host toxicosis or mortality (Széll et al. 2001; Neiffer et al. 2005; Hunter and Isaza, 2008), or kill non-target invertebrates in the ecosystem (Herd, 1995; Spratt, 1997). Thus, for many protected

* Corresponding author: School of Biological Sciences, Flinders University, PO Box 2100, Adelaide 5001, SA, Australia. Tel: +6188201 2805. Fax: +618 82013015 . E-mail: Stephanie.Godfrey@flinders.edu.au species, studies are restricted to observational 'snapshot' studies that test for negative correlations between infection and indicators of host fitness (Valera et al. 2006; Bunbury et al. 2007, 2008; Zhang et al. 2008). However, an observed negative relationship does not imply that parasites caused the reduced fitness. Immune responses are energetically demanding (Derting and Compton, 2003), so individuals with lower fitness may mount a lower immune response, making them more susceptible to infection (Navarro et al. 2003; Ujvari and Madsen, 2005). Thus high parasite loads may be associated with low host fitness without causing it.

An alternative method to determine whether parasites influence host fitness is through markrecapture studies that investigate temporal interactions between parasitism and indicators of host fitness. An association between high parasite load and a subsequent decline in indicators of host fitness suggests a parasite cost (Bull and Burzacott, 2006; Burthe et al. 2008). Recapture studies also allow tests of the alternative hypothesis that lower fitness leads to increased susceptibility to parasites (Appleby et al. 1999; Clobert et al. 2000). However, relatively few studies have used temporal patterns to test both hypotheses (but see: Dawson and Bortolotti, 2001; 
Beldomenico et al. 2008). Studies that investigate sequential associations between infection and indicators of host fitness may also reveal the temporal nature of parasite impacts on hosts. Ectoparasitic ticks and mites (Acari) show seasonal patterns of attachment in temperate climates, with high levels of synchronous feeding over short periods of time (Oliver, 1989). Thus, the costs of ectoparasites to hosts are likely to be greatest when ectoparasite attachment and feeding is at a peak (Lourenco and Palmeirim, 2007). Conducting the study at biologically relevant periods not only allows effective testing of the hypotheses, but also provides insights into when the costs of parasites are likely to be greatest. Although these studies remain observational, and the trends may be affected by other co-varying factors, some level of causality can be inferred. They represent a compromise where experimental manipulations of parasites on hosts are ethically impractical.

We investigated interactions between ectoparasite infestation and body condition in the tuatara (Sphenodon punctatus). This host species is the only extant representative of the primitive reptilian lineage Rhynchocephalia (Hay et al. 2009). Once widespread across mainland New Zealand, its extant natural range is now restricted to 32 island populations (Gaze, 2001). It is listed as 'range restricted' with the New Zealand Department of Conservation, and is legally protected (Gaze, 2001). Tuatara are infected by a host-specific tick (Amblyomma sphenodonti) (Dumbleton, 1943; Klompen et al. 2002), and 2 species of trombiculid mites (Neotrombicula sphenodonti and N. naultini) (Goff et al. 1987). Despite intense conservation management of the host species (Gaze, 2001), little is known of the impact of endemic parasites on tuatara. One survey of the health of tuatara prior to a translocation found no relationship between body condition and tick infestation (Burnham et al. 2006) while a second survey reported a positive relationship (Ruffell, 2005). Although these studies found no indication of a negative impact of ectoparasites on tuatara, the reported tick burdens were low. We expanded on the previous studies to explore interactions between host body condition and ectoparasite loads in a natural population of tuatara, when ectoparasite loads were at their highest and thus, likely to have the greatest impact on host fitness. We used both 'snap shot' observations and temporal patterns of ectoparasite infestation in recaptured individuals to test 3 inter-related hypotheses. Our first hypothesis (1) was that at the peak of parasite infestation there would be a negative relationship between parasite load and host body condition. This is the snap shot observation commonly used to infer an impact of parasites on hosts. However this negative relationship might result from less fit individuals being less resistant to infestation. Our second hypothesis (2) tested this by predicting that hosts with lower body condition before the peak would become infested by more parasites in the peak. Alternatively, the snapshot observation may be explained by parasites reducing host condition. Our third hypothesis (3) tested this by predicting hosts with higher loads in the peak would decline more in body condition after the peak. Thus our 3 hypotheses involved exploring trends, or relationships, over different times in a cycle of ectoparasite infection.

\section{MATERIALS AND METHODS}

\section{Parasite species biology}

Tuatara ticks develop from an egg into larva, nymph and then adult, and feed on tuatara blood during each stage (Heath, 2006). After engorgement, each stage detaches from the host to moult into the next life-cycle stage, or if a female, to lay eggs (Heath, 2006). Adult male ticks do not engorge, but remain on the host for mating. On Stephens Island, New Zealand, ticks are found attached to hosts at all times of the year ( $>97 \%$ tuatara infected), but vary seasonally in abundance. Tick loads are lowest over the austral summer, attachment increases over autumn (March-May) to peak by early spring (September) when tick feeding is triggered by warmer temperatures, and tick loads subsequently decline from September to November (Godfrey et al. 2008) (Fig. 1). Tuatara are less active over winter (June-August (Walls, 1981, 1983)), when tick development is suspended (Godfrey et al. 2008).

The 2 mite species are not easily distinguished during visual inspection of a host, so in this study we refer to them as mites. They have a similar life cycle to ticks, but are only parasitic in the larval stage. Free-living nymphs and adults are probably predatory, feeding on small invertebrates in the leaf litter and soil (Wharton, 1952; Sasa, 1961). The prevalence and intensity of mite infections are more seasonal than ticks, with larval mites appearing on hosts in summer (January), peaking in March, and declining in late autumn (May) (Godfrey et al. 2008) (Fig. 1).

\section{Field study}

We explored associations between ectoparasite loads and body condition in a mark-recapture study of tuatara on Stephens Island (Cook Strait, New Zealand, $\left.40^{\circ} 40^{\prime}, 174^{\circ} 0^{\prime}\right)$. We surveyed tuatara 6 times from January 2005 to November 2006 (Table 1). Our surveys included the pre-peak, peak, and post-peak infection periods of each ectoparasite (Table 1, Fig. 1). Tuatara were captured within three $20 \mathrm{~m}$ diameter circular study plots in closed-canopy forest habitat. Each survey was conducted over 4 to 11 nights (mean 5.8, 1.2 SE). Each night, we searched plots for 2-8 h, depending on tuatara activity, and the number of tuatara already captured during the 
Table 1. Number of adult males $\left(N_{M}\right)$, adult (non-gravid) females $\left(N_{F}\right)$, and total adult tuatara (Sphenodon punctatus) $\left(N_{\text {total }}\right)$ captured in surveys during the pre-peak, peak ${ }^{1}$ and post-peak infection periods for each ectoparasite, and the number of tuatara recaptured in both the pre-peak and peak parasite surveys ${ }^{2}$, the peak and post-peak surveys ${ }^{3}$, and over the whole sampling period for each ectoparasite

(Superscript numbers (1,2 and 3) correspond with the survey periods shown in Fig. 1, and the data used to test our hypotheses; (1) at the peak of parasite infestation there would be a negative relationship between parasite load and host body condition (snap shot correlation); (2) hosts with lower body condition before the peak would become infested by more parasites in the peak; and (3) hosts with higher loads in the peak would decline more in body condition after the peak.)

\begin{tabular}{|c|c|c|c|c|c|c|c|c|}
\hline \multirow[b]{2}{*}{ Infection period } & \multicolumn{4}{|c|}{ Tuatara captured for tick analyses } & \multicolumn{4}{|c|}{ Tuatara captured for mite analyses } \\
\hline & Survey & $N_{F}$ & $N_{M}$ & $N_{\text {total }}$ & Survey & $N_{F}$ & $N_{M}$ & $N_{\text {total }}$ \\
\hline Pre-peak & March 2006 & 34 & 51 & 85 & January 2005 & 67 & 76 & 143 \\
\hline Peak $^{1}$ & September 2006 & 34 & 26 & 60 & March 2005 & 52 & 57 & 109 \\
\hline Post-peak & November 2006 & 28 & 56 & 84 & May 2005 & 40 & 52 & 92 \\
\hline \multicolumn{9}{|l|}{ Recaptures } \\
\hline Pre-peak - Peak ${ }^{2}$ & Mar-Sept 2006 & 23 & 9 & 32 & Jan-Mar 2005 & 37 & 42 & 79 \\
\hline Peak - Post-peak ${ }^{3}$ & Sept-Nov 2006 & 31 & 11 & 42 & Mar-May 2005 & 34 & 30 & 64 \\
\hline Over entire period & Mar-Sept-Nov 2006 & 23 & 7 & 30 & Jan-Mar-May 2005 & 28 & 28 & 56 \\
\hline
\end{tabular}

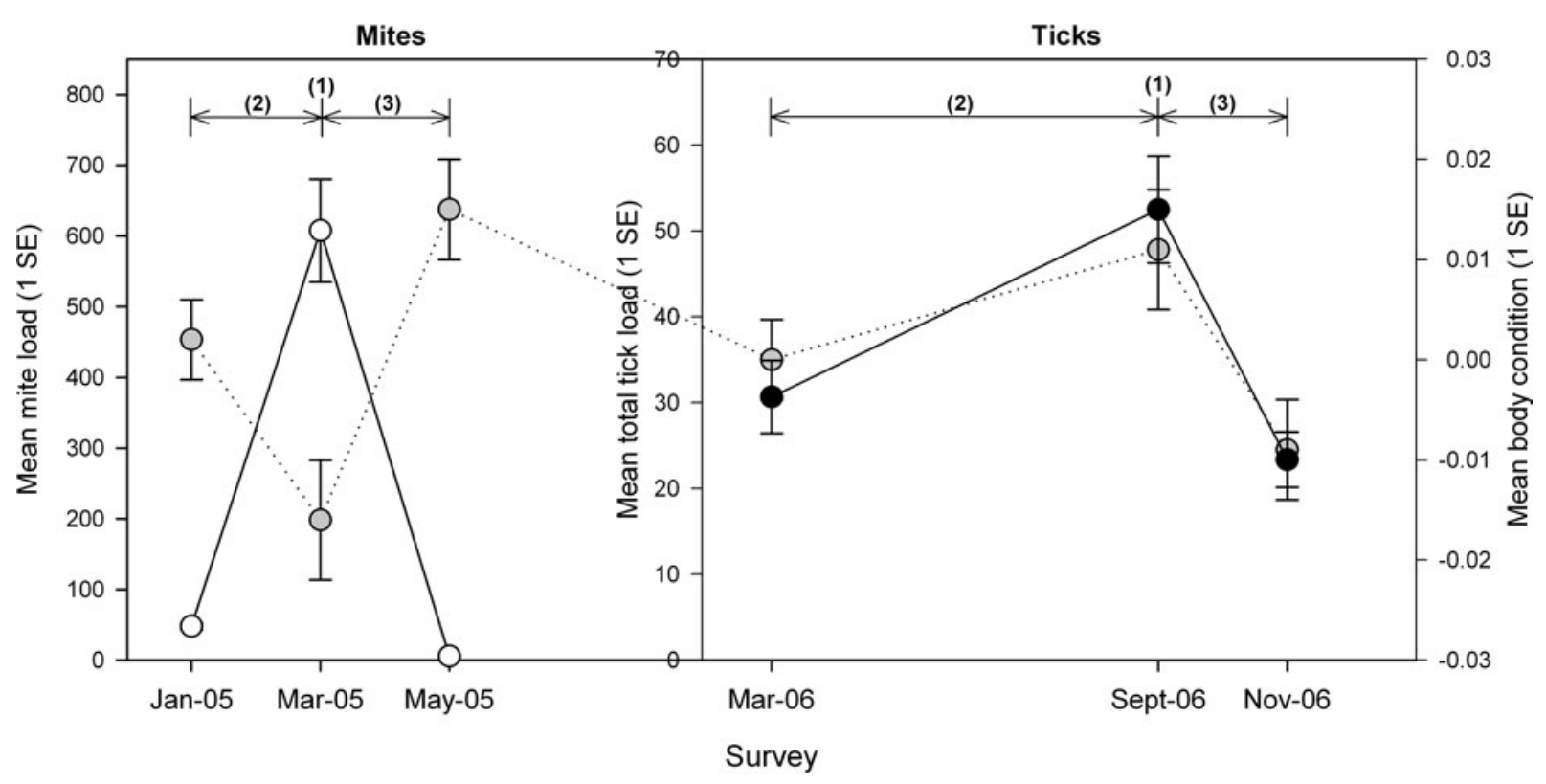

Fig. 1. Mean body condition (grey circles, dotted line, right-hand axis), mean mite (Neotrombicula spp.) loads (open circles) and mean tick (Amblyomma sphenodonti) loads (filled circles) of tuatara (Sphenodon punctatus) among surveys (Table 1). Numbers indicate the hypotheses tested in our study; (1) the 'snap shot' correlation between body condition and ectoparasite loads during peak parasite infestation; temporal associations, comparing (2) body condition before the peak with subsequent changes in ectoparasite loads, and (3) ectoparasite loads during the peak with subsequent changes in body condition. Tuatara were infested by ticks year round, and mites in March 2006. These data were presented by Godfrey et al. 2008.

survey. Additional sampling took place during daylight on some days in the survey period. New animals were marked with a subdermal Passive Integrated Transponder (PIT) tag (Allflex, NZ). Individuals were captured once within a survey, and recaptures between surveys were identified by scanning individuals and reading the PIT tag number. At each capture, we recorded the size (snout to vent length (SVL, mm)), sex (male, female or subadult (SVL $<170 \mathrm{~mm})$ ), mass $(\mathrm{g})$ and the total number of ticks and mites attached. Ectoparasites were not removed from hosts. We also distinguished between the different tick stages (larvae, nymphs and adults), and determined the sex of adult ticks. Mite loads above 50-100 were derived by estimating the area of the host that contained 100 mites, and visually extrapolating this estimate across the entire infected area of the animal surface.

Although tick loads may change over short periods (days) in some tick species (Oliver, 1989), the low 
temperatures on Stephens Island probably increased the feeding time of tuatara ticks on their ectothermic host. In March, larval and nymphal ticks remained attached for at least 10 days (S. Godfrey, unpublished data), and in another study, adult females remained attached for a minimum of 20 days (mean 57 days) (Heath, 2006). Tick loads of individuals in spring (September) were closely correlated with those in the previous winter (June), indicating that infestation levels are highest before winter, ticks remain attached over winter, and loads decline after September (Godfrey et al. 2008). Thus, we considered that the measure of tick loads used in this study adequately represented actual tick loads.

We calculated an index of tuatara body condition from the residuals of a linear regression between log-transformed mass and log-transformed SVL. The use of mass-size residuals as an index of body condition has been criticized for generating spurious relationships between condition and other size-related measures, particularly where mass is not linearly related to body size (Green, 2001; Freckleton, 2002; Schulte-Hostedde et al. 2005). However, with careful testing of assumptions, body condition indices are useful, non-destructive indicators of body mass relative to size (Stevenson and Woods, 2006). This index of body condition has been used previously for tuatara (Hoare et al. 2006; Moore et al. 2007), for other reptiles (Platenberg and Griffiths, 1999; Lebas and Marshall, 2001 ; Connolly and Cree, 2008) and widely in other taxa (Millán et al. 2004; Birkhead et al. 2006; Barnes et al. 2007; Püttker et al. 2008). The index used in our study meets the assumption of linearity $\left(r^{2}=0 \cdot 90\right)$.

\section{Statistical analyses}

Ticks and mites differed in the time of peak infestation (Table 1, Fig. 1). For ticks, we used data from March 2006 (pre-peak), September 2006 (peak), and November 2006 (post-peak). For mites, we used data from January 2005 (pre-peak), March 2005 (peak), and May 2005 (post-peak). Note, we did not conduct surveys during the 2005 peak and decline period for ticks, or for periods immediately before or after the 2006 peak for mites. We omitted juvenile and subadult tuatara $(n=6)$ and gravid females $(n=4)$ from analyses.

\section{(1) Associations between body condition and ectoparasite load}

We used linear mixed effect models (lme) in $\mathrm{R}$ (R Core Development Team, 2007) to test for an association between body condition and ectoparasite load of tuatara when parasite loads were at a peak (ticks in September, mites in March, Table 1). Body condition was the dependent variable, sex was a fixed effect, and SVL and ectoparasite load were covariates. We log-transformed ectoparasite loads to normality. Individual hosts were nested within study plots as random effects. We began with a maximal model including all main effects, 2-way and 3-way interactions, and reduced the model by removing non-significant terms until further reductions resulted in significant changes in deviance. Changes in deviance between model reductions were tested in a likelihood ratio test with a $\chi^{2}$ statistic. Separate models were constructed for all ticks, for the different tick-feeding stages (larvae, nymphs, females), and for mites. We did not construct a model for male ticks in any analysis because males do not consume large quantities of blood and lymph like females, and are unlikely to have a direct impact on host condition.

\section{(2) Effects of body condition on changes in ectoparasite load}

We tested the hypothesis that poor body condition may reduce the resistance of individuals to parasites, leading to increased parasite burdens. We used a linear mixed effects model (as described above) to compare body condition in the survey prior to the peak in parasite load (ticks in March, mites in January, Table 1), with the subsequent change in ectoparasite load (Fig. 1). Change in ectoparasite load was calculated by subtracting ectoparasite load of each individual in the pre-peak survey from its ectoparasite load during the peak for individual hosts captured in both surveys. In this model, change in ectoparasite load was the dependent variable, sex was a fixed effect, and SVL and body condition in the prior survey were covariates. Individual hosts were nested within study plots as random effects. We logtransformed changes in nymph, female and mite loads, and square-root transformed changes in total tick load to normality. Separate models were constructed for all ticks, for the different tick stages (larvae, nymphs, females), and for mites. Since the predictor variables SVL and BC may be correlated, we also constructed the same models without SVL, to test if our results were affected by multicollinearity.

\section{(3) Effects of ectoparasites on subsequent changes in body condition}

We tested the hypothesis that high ectoparasite loads would reduce host body condition by comparing ectoparasite loads in the peak parasite survey with subsequent changes in body condition. Changes in body condition were calculated by subtracting body condition of each individual in the post-peak survey (ticks in November, mites in May, Table 1) from its body condition in the peak survey for individual hosts captured in both surveys. This analysis was similar to the previous analysis, but change in body condition was the dependent variable, sex was a fixed effect, and SVL and ectoparasite load in the peak 
Table 2. Results of mixed model analyses testing the effects of tick loads (Amblyomma sphenodonti) (total ticks, larval ticks, nymphal ticks and female ticks), sex and size (SVL) on the body condition of tuatara (Sphenodon punctatus) during the peak parasite period (September 2006)

(Only terms remaining in the minimal model are shown, and terms in bold are significant $(P<0 \cdot 05)$. The model for mites is not shown because no terms remained in the minimal model.)

\begin{tabular}{|c|c|c|c|c|c|c|c|c|c|}
\hline & \multirow[b]{2}{*}{ D.F. } & \multicolumn{2}{|c|}{ Total ticks } & \multicolumn{2}{|c|}{ Larval ticks } & \multicolumn{2}{|c|}{ Nymphal ticks } & \multicolumn{2}{|c|}{ Female ticks } \\
\hline & & $\mathrm{F}$ & $P$ & $\mathrm{~F}$ & $P$ & $\mathrm{~F}$ & $P$ & $\mathrm{~F}$ & $P$ \\
\hline Sex & 1 & $1 \cdot 65$ & $0 \cdot 203$ & $1 \cdot 74$ & $0 \cdot 192$ & $1 \cdot 85$ & $0 \cdot 179$ & $1 \cdot 69$ & $0 \cdot 198$ \\
\hline SVL & 1 & $8 \cdot 17$ & $0 \cdot 006$ & $7 \cdot 49$ & 0.008 & $8 \cdot 14$ & $0 \cdot 006$ & $6 \cdot 37$ & 0.014 \\
\hline Ectoparasites & 1 & $7 \cdot 61$ & $0 \cdot 008$ & $4 \cdot 70$ & 0.034 & $8 \cdot 37$ & $0 \cdot 005$ & & \\
\hline Sex $\times$ SVL & 1 & $6 \cdot 48$ & $0 \cdot 014$ & $5 \cdot 32$ & 0.025 & $6 \cdot 76$ & $0 \cdot 012$ & $4 \cdot 75$ & 0.033 \\
\hline Sex $\times$ Ectoparasites & 1 & $0 \cdot 38$ & 0.539 & $0 \cdot 25$ & $0 \cdot 616$ & 1.97 & $0 \cdot 165$ & & \\
\hline $\mathrm{SVL} \times$ Ectoparasites & 1 & $6 \cdot 73$ & $0 \cdot 012$ & $5 \cdot 24$ & $0 \cdot 026$ & $3 \cdot 87$ & $0 \cdot 054$ & & \\
\hline Residual D.F. & & 51 & & 51 & & 51 & & 54 & \\
\hline
\end{tabular}

period were covariates. Individual hosts were nested within study plots as random effects. Ectoparasite loads were log-transformed to normality.

RESULTS

\section{(1) Associations between body condition and ectoparasite load}

Tick loads were significantly negatively related to body condition of tuatara in September (Table 2). Individuals with more ticks were in poorer condition (Fig. 2). There was also a negative effect of SVL on body condition of tuatara $(\beta=-0 \cdot 0002)$; however, tick load explained more variation in body condition $\left(r^{2}=0 \cdot 052\right)$ than SVL $\left(r^{2}=0 \cdot 0006\right)$. There was a significant interaction between tuatara SVL and tick load on body condition. The negative relationship between tick load and body condition was stronger for larger individuals than smaller individuals (Fig. 2). Although there was no effect of sex on body condition, there was a significant interaction between SVL and sex. Female body condition was more strongly negatively related to SVL $(\beta=-0.001$, $\left.r^{2}=0 \cdot 181\right)$ than male body condition $(\beta=-0.0004$, $\left.r^{2}=0 \cdot 046\right)$.

Both larvae and nymph loads in September were significantly negatively related to body condition of tuatara (Table 2), however the model for nymphs explained more variation $\left(r^{2}=0 \cdot 057\right)$ than the model for larvae $\left(r^{2}=0 \cdot 031\right)$. Female tick loads in September had no effect on the body condition of tuatara.

Mite loads were not related to body condition of tuatara in March. Host sex and SVL, and interactions among sex, SVL and mite loads had no effect on body condition of tuatara in March.

\section{(2) Effects of body condition on changes in ectoparasite load}

Body condition in March had no effect on subsequent changes in total tick load from March to

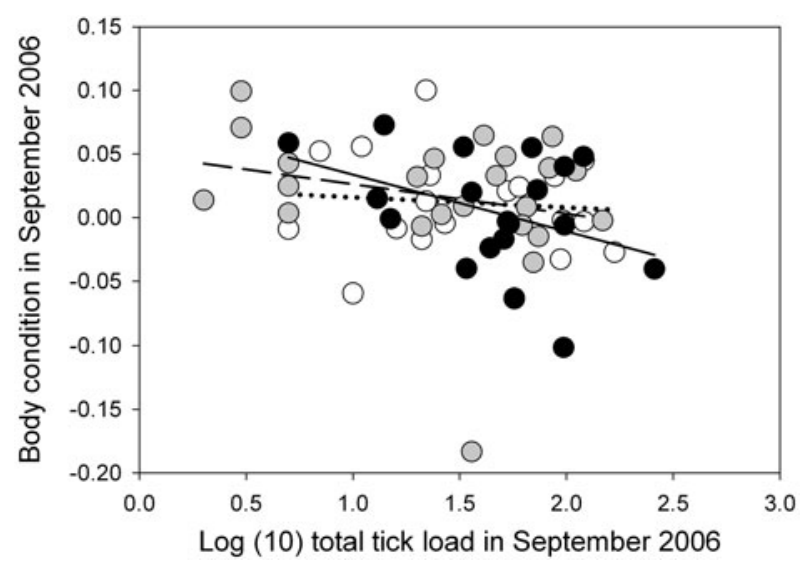

Fig. 2. Negative relationship between tick (Amblyomma sphenodonti) loads and body condition of tuatara (Sphenodon punctatus) in September $2006(n=60)$ for small (SVL $<200 \mathrm{~mm}$, open circle, dotted line), medium (SVL $>200$ and $<230 \mathrm{~mm}$, grey circle, dashed line), and large (SVL $>230 \mathrm{~mm}$, black circle, solid line) tuatara.

September or on changes in any of the tick life-cycle stages (Table 3). No other factors or interactions influenced change in overall tick load.

However, an interaction between body condition and sex had a significant effect on changes in larvae and nymph loads (Table 3, Fig. 3). This result remained robust when SVL was removed from the models to allow for possible multicollinearity. Male tuatara showed no relationship between body condition in March and changes in larvae $\left(r_{p}=-0 \cdot 106\right.$, $t=-0 \cdot 490$, D.F. $=21, P=0 \cdot 629)$ or nymphs $\left(r_{p}=\right.$ $0 \cdot 012, t=0 \cdot 055$, D.F. $=21, P=0 \cdot 956)$. However, female tuatara in better body condition gained more larvae $\left(r_{s p}=0 \cdot 6, \mathrm{~S}=48, n=9, P=0 \cdot 096\right.$, Fig. 3a), and fewer nymphs $\left(r_{s p}=-0.616, \mathrm{~S}=194, \quad n=9, \quad P=\right.$ $0 \cdot 085$, Fig. $3 \mathrm{~b}$ ), than those in poorer body condition. The trends were only marginally significant and may have resulted from a much smaller sample size for females than males (Table 1). 
Table 3. Results of mixed model analyses testing the effects of sex, size (SVL) and body condition (BC) of tuatara (Sphenodon punctatus) in the pre-peak survey (March 2006 for ticks (Amblyomma sphenodonti), January 2005 for mites (Neotrombicula spp.)), on subsequent changes in ectoparasite load (total ticks, larval ticks, nymphal ticks and mites)

(Only terms remaining in the minimal model are shown, and terms in bold are significant $(P<0 \cdot 05)$. The model for female ticks is not shown because no terms remained in the minimal model.)

\begin{tabular}{|c|c|c|c|c|c|c|c|c|c|}
\hline & \multirow[b]{2}{*}{ D.F. } & \multicolumn{2}{|c|}{ Total ticks } & \multicolumn{2}{|c|}{ Larval ticks } & \multicolumn{2}{|c|}{ Nymphal ticks } & \multicolumn{2}{|l|}{ Mites } \\
\hline & & $\mathrm{F}$ & $P$ & $\mathrm{~F}$ & $P$ & $\mathrm{~F}$ & $P$ & $\mathrm{~F}$ & $P$ \\
\hline Sex & 1 & $1 \cdot 14$ & $0 \cdot 295$ & $0 \cdot 24$ & $0 \cdot 626$ & $2 \cdot 42$ & $0 \cdot 131$ & & \\
\hline SVL & 1 & $0 \cdot 26$ & $0 \cdot 612$ & & & & & $18 \cdot 46$ & $<0.001$ \\
\hline $\mathrm{BC}$ & 1 & $0 \cdot 04$ & $0 \cdot 837$ & $0 \cdot 32$ & $0 \cdot 571$ & $1 \cdot 04$ & $0 \cdot 316$ & & \\
\hline Sex $\times$ BC & 1 & $0 \cdot 39$ & $0 \cdot 534$ & $6 \cdot 31$ & 0.018 & $7 \cdot 12$ & $0 \cdot 012$ & & \\
\hline $\mathrm{SVL} \times \mathrm{BC}$ & 1 & $0 \cdot 59$ & $0 \cdot 449$ & & & & & & \\
\hline Sex $\times$ SVL $\times$ BC & 1 & $3 \cdot 37$ & $0 \cdot 079$ & & & & & & \\
\hline Residual D.F. & & 23 & & 26 & & 26 & & 75 & \\
\hline
\end{tabular}
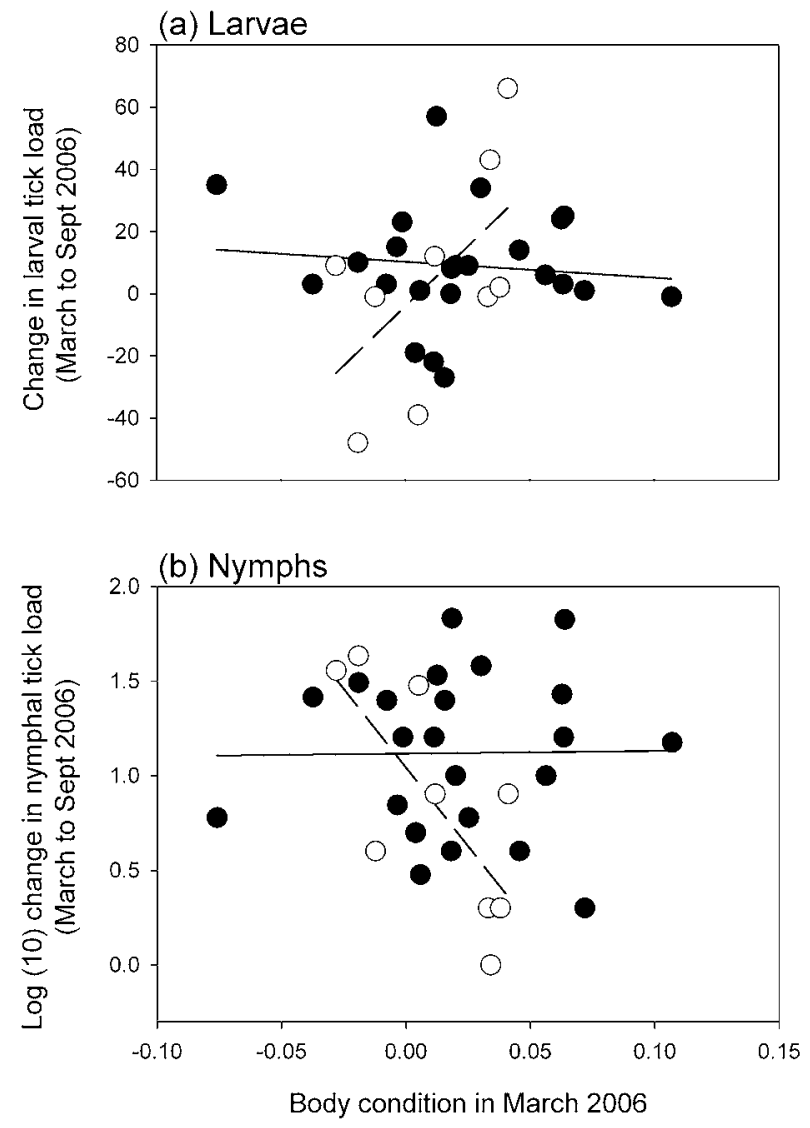

Fig. 3. Relationships between body condition of tuatara (Sphenodon punctatus) in March 2006 and subsequent changes in (a) larval tick (Amblyomma sphenodonti) load, and (b) nymphal tick load from March to September for male (filled circle, solid line, $n=23$ ) and female tuatara (open circle, dashed line, $n=9$ ). Change in larval and nymphal tick loads were calculated for each individual by subtracting its load in March from its load in September.

Body condition in January had no effect on changes in mite load between January and March (Table 3). Only SVL remained in the model, with larger individuals gaining more mites $(\beta=0.006$, $\left.r^{2}=0 \cdot 171\right)$.

\section{(3) Effects of ectoparasites on changes in body condition}

Both overall tick load and larval tick load in September had a significant effect on changes in body condition from September to November (Table 4). Tuatara with higher tick loads declined more in body condition (Fig. 4). Larval load explained more variation in body condition $\left(r^{2}=0 \cdot 191\right)$ than the model for total tick loads $\left(r^{2}=0 \cdot 074\right)$. The change in body condition between September and November translated into more than $\pm 5 \%$ change in body mass. The other tick life-cycle stages had no significant effect on changes in body condition.

Mite loads of tuatara in March had no main effect on subsequent changes in body condition between March and May, but there was a significant threeway interaction between sex, SVL and mite load (Table 4). Smaller males decreased in body condition if they had higher mite loads, but larger males did not (Fig. 5). There was no equivalent effect in female tuatara.

\section{DISCUSSION}

In September, at the peak of tick infestation and feeding, tuatara with higher tick loads were in poorer condition, and those hosts declined further in condition between September and November. The relationship was particularly strong for larval ticks, which are the most abundant tick life-cycle stage on tuatara (Godfrey et al. 2008). Tick loads (particularly larvae) declined sharply between September and November as ticks engorged and detached (Godfrey et al. 2008). The decline in body condition associated with high total tick and larval loads probably resulted from the energetic demands associated with the 
Table 4. Results of mixed model analyses testing the effects of sex, size (SVL), and ectoparasite load (total ticks (Amblyomma sphenodonti), larval ticks and mites (Neotrombicula spp.)) in the peak parasite survey (September 2006 for ticks and tick life-cycle stages, March 2005 for mites) on subsequent changes in body condition of tuatara (Sphenodon punctatus)

(Only terms remaining in the minimal model are shown, and terms in bold are significant $(P<0 \cdot 05)$. The models for nymph and female ticks are not shown because no terms remained in the minimal model.)

\begin{tabular}{|c|c|c|c|c|c|c|c|}
\hline & \multirow[b]{2}{*}{ D.F. } & \multicolumn{2}{|c|}{ Total ticks } & \multicolumn{2}{|c|}{ Larval ticks } & \multicolumn{2}{|l|}{ Mites } \\
\hline & & $\mathrm{F}$ & $P$ & $\mathrm{~F}$ & $P$ & $\mathrm{~F}$ & $P$ \\
\hline Sex & 1 & $0 \cdot 58$ & $0 \cdot 450$ & $0 \cdot 66$ & $0 \cdot 419$ & $4 \cdot 70$ & $0 \cdot 034$ \\
\hline SVL & 1 & $3 \cdot 35$ & $0 \cdot 075$ & $3 \cdot 82$ & $0 \cdot 058$ & $0 \cdot 42$ & $0 \cdot 518$ \\
\hline Ectoparasites & 1 & $7 \cdot 79$ & $0 \cdot 008$ & $14 \cdot 27$ & $<0.001$ & $0 \cdot 26$ & $0 \cdot 608$ \\
\hline Sex × SVL & 1 & & & & & $2 \cdot 85$ & $0 \cdot 096$ \\
\hline Sex $\times$ Ectoparasites & 1 & & & & & $0 \cdot 30$ & $0 \cdot 582$ \\
\hline SVL $\times$ Ectoparasites & 1 & & & & & $0 \cdot 001$ & $0 \cdot 967$ \\
\hline Sex $\times$ SVL $\times$ Ectoparasites & 1 & & & & & $4 \cdot 24$ & $0 \cdot 044$ \\
\hline Residual D.F. & & 36 & & 36 & & 24 & \\
\hline
\end{tabular}
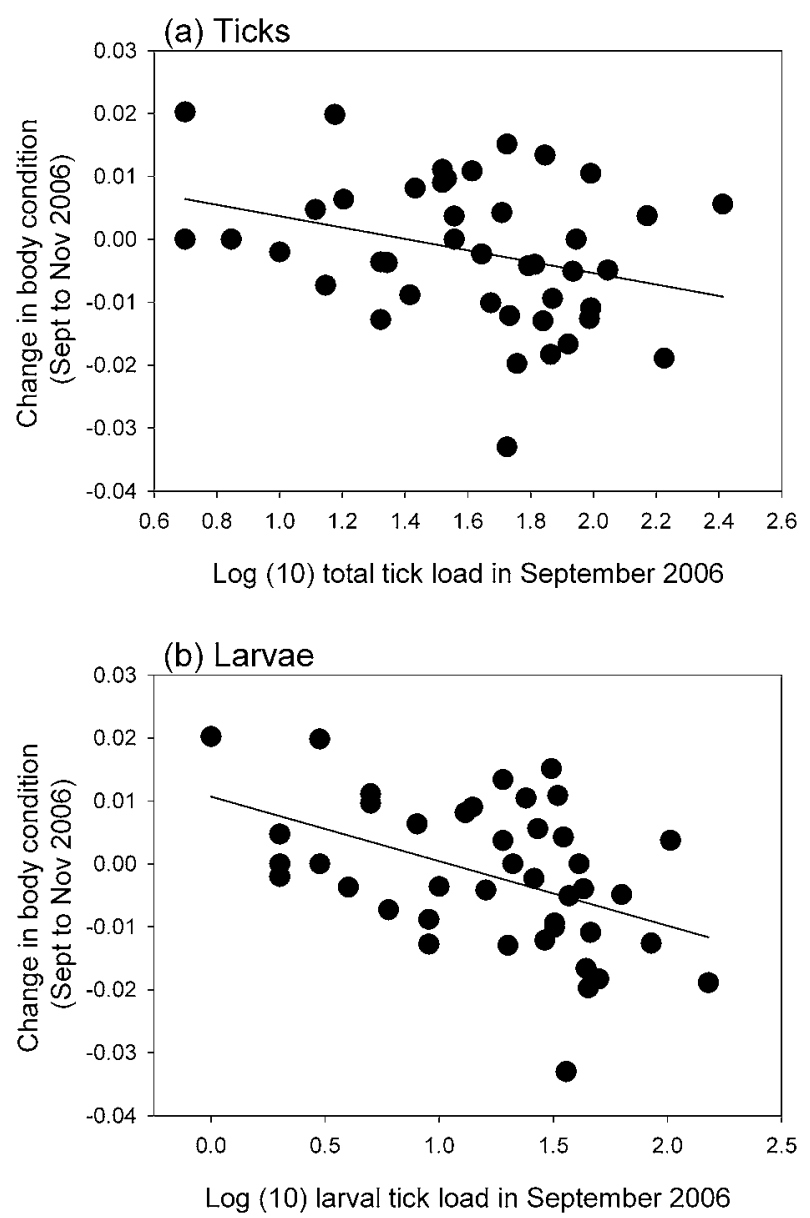

Fig. 4. Negative relationship between (a) total tick (Amblyomma sphenodonti) loads and (b) larval tick loads in September 2006, and subsequent changes in body condition of tuatara (Sphenodon punctatus) from September 2006 to November $2006(n=42)$. Change in body condition was calculated for each individual by subtracting its body condition in September from its body condition in November.

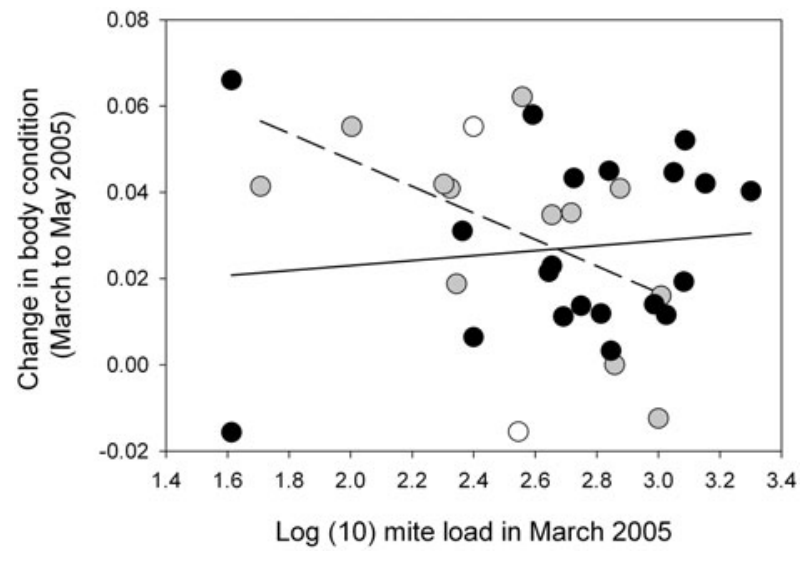

Fig. 5. Relationship between mite (Neotrombicula spp.) load in March and subsequent change in body condition of tuatara (Sphenodon punctatus) from March 2005 to May 2005 for small (SVL $<200 \mathrm{~mm}$, open circle), medium (SVL $>200$ and $<230 \mathrm{~mm}$, grey circle, dashed line), and large (SVL $>230 \mathrm{~mm}$, black circle, solid line) male tuatara $(n=34)$. Change in body condition was calculated for each individual by subtracting its body condition in March from its body condition in May.

synchronous feeding of many ticks over this short period. Leukocyte levels are elevated in tuatara with higher tick loads (Burnham et al. 2006), thus additional energetic demands from an immune response to high tick loads may also contribute to the decline in condition.

When testing the alternate hypothesis, we found a marginal effect of body condition on changes in larval and nymphal tick loads of female tuatara. This could reflect differences in the timing of infestation periods, since larvae attach earlier (NovemberMarch) than nymphs (March-May) (Godfrey et al. 2008). Thus our measure of body condition may be 
more relevant to changes in nymph loads than larvae. Since the sample size for female hosts was small, more data are necessary to clarify whether body condition may affect the susceptibility of female tuatara to infestation by nymphal ticks.

Feeding by mites is highly synchronized in March (Godfrey et al. 2008), but we detected no overall effect of mite loads in March on subsequent changes in body condition from March to May. Mite loads in 2005 were the highest observed over a 3 -year study (Godfrey et al. 2008), suggesting our finding did not result from unusually low mite loads. Nevertheless, we found an effect only among small males, where those with more mites lost more body condition. Ectoparasites could be more costly to smaller hosts since they harbour more parasites per unit body surface area than larger individuals with equivalent loads (Hart et al. 1992; Mooring and Hart, 1997; Hawlena et al. 2006). Also, smaller males are less socially dominant, and may be under greater social stress in March, when mating and territorial behaviour is at a peak (Moore et al. 2009).

These findings are consistent with the hypothesis that ectoparasites reduce the body condition of tuatara, and provide little evidence to suggest that host body condition affects susceptibility to infestation. Susceptibility to infection could be influenced on a seasonal level by seasonal changes in body condition or hormones. Body condition of tuatara declines between January and March (Moore et al. 2007) in the same period when testosterone levels of males and breeding females peak (Cree et al. 1992). This period is just before tick infestation begins to increase, and coincides with the time when mite loads are highest (Godfrey et al. 2008). In reptiles, increased testosterone levels are associated with increased susceptibility to parasite infection (Klukowski and Nelson, 2001; Roberts et al. 2004; Cox and John-Alder, 2007). Thus, on a seasonal level, either reduced body condition or increased hormone levels could enhance host susceptibility to ectoparasite infestation. However, other factors may influence individual variability in host susceptibility to ectoparasite infestation. Ectoparasite infection results from contact between hosts and free-living infectious stages, so host behaviour could influence individual exposure to ectoparasites, and consequently infestation patterns. Individual variation in hormone levels, particularly testosterone may then influence immunity to infection. These variable factors in transmission success require further research.

Our study highlights the advantage of temporal comparisons in understanding the causality of correlations between infection level and condition (ticks), and in detecting more subtle effects of parasites where correlations were not observed (mites). However, our study remains observational, and results could be affected by other co-varying factors.
For example, if higher parasite prevalence coincided with poor quality habitats, then reduced body condition could result from restricted resources rather than parasite infection. However, our study was conducted across 3 closed canopy forest study plots that had similar microclimatic conditions and resource quality, thus environmental gradients are unlikely to confound our findings. Alternatively, if high tick loads are also associated with a form of physiological stress, then the stress may cause the decline in condition rather than, or in addition to, tick loads. However, we would expect a strong effect of body condition on changes in parasite loads if this were the case, which we did not detect. Over the period that body condition declined (SeptemberNovember), tick loads also declined, suggesting that a decline in body condition is not coupled with an increased susceptibility to infection. Testing both alternate hypotheses at biologically meaningful intervals should reduce the chance that the results are confounded.

\section{Impacts of parasites and conservation}

Few studies of threatened species can explore the effects of endemic parasites through experimental manipulation, thus most are limited to observational datasets to infer the costs of parasites to hosts (Valera et al. 2006; Bunbury et al. 2007, 2008; Zhang et al. 2008). Since threatened species are often subjected to numerous sources of stress (Lafferty and Kuris, 1999), negative correlations between infection and body condition could have other causes. A dynamic approach, as demonstrated in this study, has shown that ectoparasites reduce the body condition of their protected hosts. Surprisingly, this approach has rarely been used (Dawson and Bortolotti, 2001; Beldomenico et al. 2008), but has the potential to provide important insights into the impacts of parasites in natural populations.

Our findings are consistent with observational (Amo et al. 2004; Irvine et al. 2006; Lourenco and Palmeirim, 2007), and experimental (Merino et al. 2000 ; Neuhaus, 2003; Tomas et al. 2007) studies that suggest parasites can reduce the body condition of their hosts. Body condition is a non-destructive estimate of the energetic state of an individual (stored versus expended energy) (Schulte-Hostedde et al. 2005). Thus, energy deficits (negative body condition) can reduce the resources available for direct fitness-related traits, such as reproduction, growth and survival (Robb et al. 1992; Murray, 2002; Wauters et al. 2007). Condition-mediated effects of parasites on host fitness have been observed in other taxa. Wild rabbits heavily infected with mxyoma virus and intestinal helminths had reduced body mass, while body mass was positively related to female fecundity (Lello et al. 2005). Similarly, female Columbian ground squirrels with experimentally 
reduced ectoparasite loads increased their body mass and had larger litters than females that were not treated (Neuhaus, 2003). Factors that influence the body condition of tuatara have implications for reproductive frequency in tuatara. Female tuatara held under captive conditions with high resource availability can reproduce in consecutive years (Moore et al. 2008). However, on North Brother Island, where resource availability is low, female tuatara reproduce on average only once every 9 years (Mitchell et al. 2009). Ectoparasites, with similar negative effects on body condition, could also reduce the frequency of tuatara reproduction. However, long-term studies are necessary to reveal the impacts of ectoparasites on direct fitness related traits of tuatara.

High tick loads were associated with a small reduction in tuatara body mass $(\sim 5 \%)$, therefore ticks are unlikely to have a detrimental effect on the large, stable population of tuatara on Stephens Island in the short-term. Thus, the value of our findings lies in the long-term conservation management of the species. Understanding the effects of parasites on tuatara, and the magnitude of these effects, will aid conservation management decisions if changes in host-parasite dynamics lead to increased ectoparasite burdens in this, or other populations of tuatara.

Since the survival of ticks and mites is partially dependent on the microclimatic conditions of their off-host environment (Needham and Teel, 1991), factors that alter this environment may also alter the ectoparasite loads of hosts. Habitat deterioration is not a concern for tuatara since populations are located in protected reserves (Gaze, 2001). However, habitat restoration of open pastures on Stephens Island could change the microclimatic conditions of the off-host environment for ectoparasites, and subsequently their survival or transmission. Similarly, the developmental rate of acarids increases with temperature (Oliver, 1989), thus changes in climate could alter the life-cycle duration and the transmission dynamics of the ectoparasites. For example, increased temperatures in the Arctic have shortened the life cycle of parasitic nematodes, and altered the transmission dynamics of the parasite, leading to increased impacts on their wild bovid hosts (Kutz et al. 2005). Thus, monitoring host-parasite interactions is necessary to detect future changes in parasite loads. Understanding the current impacts of parasites will allow us to predict the implications of future changes in host-parasite associations. If predicted impacts pose a risk to the survival of tuatara populations, then parasite removal could be used as a conservation strategy.

However, maintaining ecological and evolutionary processes is a central aim of conservation management (Thompson, 1996; Altizer et al. 2003). Thus, unless parasites threaten the survival of these populations, it is important to retain natural host-parasite associations. Retaining parasites in host populations could maintain genetic diversity within these populations by enhancing selection pressure for fit genotypes (Altizer et al. 2003; Smith et al. 2009). This is particularly important where population densities are high, as they are on Stephens Island (Moore et al. 2007), and a novel disease may spread quickly if genetic diversity is low. Since Stephens Island tuatara are frequently used as a source population for translocations, the maintenance of a genetically robust population is particularly important in the longterm success of translocations.

Similarly, it may be beneficial to retain these ecological and evolutionary processes in the establishment of new populations of tuatara, by translocating tuatara with their parasites. However, since the ectoparasites reduce tuatara body condition, parasites could pose a risk to the success of translocations. Tuatara usually gain weight following translocations (Nelson et al. 2002; Ruffell, 2005; McKenzie, 2007), which would offset any declines in body condition caused by ticks. Furthermore, during the early stages of a newly translocated population, ectoparasite loads remain at low levels (McKenzie, 2007), since ticks are not present in the new environment to sustain infection in hosts as they would in a natural population. Thus, in the short-term, ticks are unlikely to have a significant negative effect on the success of tuatara translocations. However, the long-term consequences of translocating tuatara with their ectoparasites depends on the survival of the ectoparasites in the new environment and the transmission dynamics of the parasites, which will be the subject of further study.

The short-term negative effects of parasites involve a trade-off with long-term benefits, which should be considered in conservation management of tuatara. Careful monitoring of host-parasite interactions is required to ensure that parasites remain an important part of the ecology and evolution of the host species, and not threaten their survival.

\section{ACKNOWLEDGEMENTS}

Three anonymous reviewers provided constructive comments that improved the manuscript. We thank the Ngati Koata (Iwi for Takapourewa/Stephens Island) and the New Zealand Department of Conservation (DoC) for their support. This research was funded by grants awarded to N.J. N. by San Diego Zoo, Victoria University of Wellington Research Fund, Allan Wilson Centre for Molecular Ecology and Evolution, grants awarded to S.S. G. by the Holsworth Wildlife Research Endowment, Flinders University Overseas Field Trip Grant, Wildlife Disease Association (Australasian Section) and the Australian Society for Herpetology, and grants awarded to C.M.B. by the Australian Research Council. We also thank Susan Keall, Clare Allen, Jon deVries, Hilary Miller, Kelly Hare, Joanne Hoare, Katherine McKenzie, Jeanine Refsnider, and Kimberly Miller for assistance with field work, and Nicola Mitchell for comments on a previous version of this manuscript. This research was conducted 
under DoC research permits (LIZ0410, NM-16723-RES), and with Victoria University of Wellington animal ethics approval (permit \#2006R12). S. S. G. was supported by an Australian Postgraduate Award. All procedures carried out in this study conformed to the current laws of New Zealand.

\section{REFERENCES}

Altizer, S., Harvell, D. and Friedle, E. (2003). Rapid evolutionary dynamics and disease threats to biodiversity. Trends in Ecology and Evolution 18, 589-596.

Amo, L., Lopez, P. and Martin, J. (2004). Prevalence and intensity of haemogregarinid blood parasites in a population of the Iberian rock lizard, Lacerta monticola. Parasitology Research 94, 290-294.

Appleby, B. M., Anwar, M. A. and Petty, S. J. (1999). Short-term and long-term effects of food supply on parasite burdens in Tawny Owls, Strix aluco. Functional Ecology 13, 315-321.

Barnes, T. S., Hinds, L. A., Jenkins, D. J. and Coleman, G. T. (2007). Precocious development of hydatid cysts in a macropodid host. International Fournal for Parasitology 37, 1379-1389.

Beldomenico, P. M., Telfer, S., Gebert, S., Lukomski, L., Bennett, M. and Begon, M. (2008). Poor condition and infection: a vicious circle in natural populations. Proceedings of the Royal Society of London, B 275, 1753-1759.

Birkhead, T. R., Pellatt, E. J., Matthews, I. M., Roddis, N. J., Hunter, F. M., McPhie, F. and Castillo-Juarez, H. (2006). Genic capture and the genetic basis of sexually selected traits in the zebra finch. Evolution 60, 2389-2398.

Bull, C. M. and Burzacott, D. (2006). The influence of parasites on the retention of long-term partnerships in the Australian sleepy lizard, Tiliqua rugosa. Oecologia 146, 675-680.

Bunbury, N., Barton, E., Jones, C. G., Greenwood, A. G., Tyler, K. M. and Bell, D. J. (2007). Avian blood parasites in an endangered columbid: Leucocytozoon marchouxi in the Mauritian Pink Pigeon Columba mayeri. Parasitology 134, 797-804.

Bunbury, N., Jones, C. G., Greenwood, A. G. and Bell, D. J. (2008). Epidemiology and conservation implications of Trichomonas gallinae infection in the endangered Mauritian pink pigeon. Biological Conservation 141, 153-161.

Burnham, D. K., Keall, S. N., Nelson, N. J. and Daugherty, C. H. (2006). Effects of sampling date, gender, and tick burden on peripheral blood cells of captive and wild tuatara (Sphenodon punctatus). New Zealand Fournal of Zoology 33, 241-248.

Burthe, S., Bennett, M., Kipar, A., Lambin, X., Smith, A., Telfer, S. and Begon, M. (2008). Tuberculosis (Mycobacterium microti) in wild field vole populations. Parasitology 135, 309-317.

Clobert, J., Oppliger, A., Sorci, G., Ernande, B., Swallow, J. G. and Garland, T. (2000). Trade-offs in phenotypic traits: endurance at birth, growth, survival, predation and susceptibility to parasitism in a lizard, Lacerta vivipara. Functional Ecology 14, 675-684.
Connolly, J. D. and Cree, A. (2008). Risks of a late start to captive management for conservation: phenotypic differences between wild and captive individuals of a viviparous endangered skink (Oligosoma otagense). Biological Conservation 141, 1283-1292.

Cox, R. M. and John-Alder, H. B. (2007). Increased mite parasitism as a cost of testosterone in male striped plateau lizards Sceloporus virgatus. Functional Ecology 21, 327-334.

Cree, A., Cockrem, J. F. and Guilette, L. J. J. (1992). Reproductive cycles of male and female tuatara (Sphenodon punctatus) on Stephens Island, New Zealand. Fournal of Zoology 226, 199-217.

Dawson, R. D. and Bortolotti, G. R. (2001). Sex-specific associations between reproductive output and hematozoan parasites of American kestrels. Oecologia 126, 193-200.

Derting, T. L. and Compton, S. (2003). Immune response, not immune maintenance, is energetically costly in wild white-footed mice (Peromyscus leucopus). Physical and Biochemical Zoology 76, 744-752.

Dumbleton, L. J. (1943). A new tick from the tuatara (Sphenodon punctatus). New Zealand Fournal of Science and Technology 24, 185b-190b.

Fenner, A. and Bull, C. M. (2008). The impact of nematode parasites on the behaviour of an Australian lizard, the gidgee skink Egernia stokesii. Ecological Research 23, 897-903.

Freckleton, R. P. (2002). On the misuse of residuals in ecology: regression of residuals vs. multiple regression. Fournal of Animal Ecology 71, 542-545.

Gaze, P. (2001). Tuatara Recovery Plan: 2001-2011. DoC Biodiversity Recovery Unit.

Godfrey, S. S., Bull, C. M. and Nelson, N. J. (2008). Seasonal and spatial dynamics of ectoparasite infestation of a threatened reptile, the tuatara (Sphenodon punctatus). Medical and Veterinary Entomology 22, 374-385.

Goff, M. L., Loomis, R. B. and Ainsworth, R. (1987). Redescription of Neotrombicula naultini (Dumbleton, 1947) and descriptions of two new species of chiggers from New Zealand (Acari: Trombiculidae). New Zealand Yournal of Zoology 14, 385-390.

Green, A. J. (2001). Mass/length residuals: measures of body condition or generators of spurious results? Ecology 82, 1473-1483.

Hart, B. L., Hart, L. A., Mooring, M. S. and Olubayo, R. (1992). Biological basis of grooming behaviour in antelope: the body-size, vigilance and habitat principles. Animal Behaviour 44, 615-631.

Hawlena, H., Khokhlova, I. S., Abramsky, Z. and Krasnov, B. R. (2006). Age, intensity of infestation by flea parasites and body mass loss in a rodent host. Parasitology 133, 187-193.

Hay, J. M., Sarre, S. D., Lambert, D. M., Allendorf, F. W. and Daugherty, C. H. (2009). Genetic diversity and taxonomy: a reassessment of species designation in tuatara (Sphenodon: Reptilia). Conservation Genetics (in the Press) doi : 10.1007/s10592-009-9952-7

Heath, A. C. G. (2006). A reptile tick, Aponomma sphenodonti Dumbleton (Acari: Ixodidae), parasitic on the tuatara, Sphenodon punctatus Gray 
(Reptilia: Rhyncocephalia), in New Zealand: observations on its life history and biology. Systematic and Applied Acarology 11, 3-12.

Herd, R. (1995). Endectocidal drugs: ecological risks and counter-measures. International Fournal for Parasitology 25, 875-885.

Hoare, J. M., Pledger, S., Keall, S. N., Nelson, N. J., Mitchell, N. J. and Daugherty, C. H. (2006). Conservation implications of a long-term decline in body condition of the Brothers Island tuatara (Sphenodon punctatus). Animal Conservation 9, 456-462.

Hoodless, A. N., Kurtenbach, K., Nuttall, P. A. and Randolph, S. E. (2002). The impact of ticks on pheasant territoriality. Oikos 96, 245-250.

Hunter, R. P. and Isaza, R. (2008). Concepts and issues with interspecies scaling in zoological pharmacology. Fournal of Zoo and Wildlife Medicine 39, 517-526.

Irvine, R. J., Corbishley, H., Pilkington, J. G. and Albon, S. D. (2006). Low-level parasitic worm burdens may reduce body condition in free-ranging red deer (Cervus elaphus). Parasitology 133, 465-475.

Klompen, H., Dobson, S. J. and Barker, S. C. (2002). A new subfamily, Bothriocrotoninae n. subfam., for the genus Bothriocroton Keirans, King \& Sharrad, 1994 status amend. (Ixodida: Ixodidae), and the synonymy of Aponomma Neumann, 1899 with Amblyomma Koch, 1844. Systematic Parasitology 53, 101-107.

Klukowski, M. and Nelson, C. E. (2001). Ectoparasite loads in free-ranging northern fence lizards, Sceloporus undulatus hyacinthinus: effects of testosterone and sex. Behavioral Ecology and Sociobiology 49, 289-295.

Kutz, S. J., Hoberg, E. P., Polley, L. and Jenkins, E. J. (2005). Global warming is changing the dynamics of Arctic host-parasite systems. Proceedings of the Royal Society of London, B 272, 2571-2576.

Lafferty, K. D. and Kuris, A. M. (1999). How environmental stress affects the impacts of parasites. Limnology and Oceanography 44, 925-931.

Lebas, N. R. and Marshall, N. J. (2001). No evidence of female choice for a condition-dependent trait in the agamid lizard, Ctenophorus ornatus. Behaviour 138, 965-980.

Lello, J., Boag, B. and Hudson, P. J. (2005). The effect of single and concomitant pathogen infections on condition and fecundity of the wild rabbit (Oryctolagus cuniculus). International fournal for Parasitology 35, 1509-1515.

Lourenco, S. I. and Palmeirim, J. M. (2007). Can mite parasitism affect the condition of bat hosts? Implications for the social structure of colonial bats. Fournal of Zoology 273, 161-168.

Main, A. and Bull, C. M. (2000). The impact of tick parasites on the behaviour of the lizard Tiliqua rugosa. Oecologia 122, 574-581.

McCallum, H. and Dobson, A. (1995). Detecting disease and parasite threats to endangered species and ecosystems. Trends in Ecology and Evolution 10, 190-194.

McKenzie, K. L. (2007). Returning tuatara (Sphenodon punctatus) to the New Zealand mainland. M.Sc. thesis, Victoria University of Wellington, Wellington, New Zealand.
Merino, S., Moreno, J., Sanz, J. J. and Arriero, E. (2000). Are avian blood parasites pathogenic in the wild? A medication experiment in blue tits (Parus caeruleus). Proceedings of the Royal of London, B, 267, 2505-2510.

Millán, J., Gortazar, C., Martín-Mateo, M. P. and Villafuerte, R. (2004). Comparative survey of the ectoparasite fauna of wild and farm-reared red-legged partridges (Alectoris rufa), with an ecological study in wild populations. Parasitology Research 93, 79-85.

Mitchell, N. J., Allendorf, F. W., Keall, S. N., Daugherty, C. H. and Nelson, N. J. (2009). Demographic effects of temperature-dependent sex determination: will tuatara survive global warming? Global Change Biology (in the Press) doi: 10.111/ j.1365-2486.2009.01964.x

Moore, J. A., Daugherty, C. H., Godfrey, S. S. and Nelson, N. J. (2009). Seasonal monogamy and multiple paternity in a wild population of a territorial reptile (tuatara). Biological Fournal of the Linnean Society 98, 161-170.

Moore, J. A., Hoare, J. M., Daugherty, C. H. and Nelson, N. J. (2007). Waiting reveals waning weight: Monitoring over 54 years shows a decline in body condition of a long-lived reptile (tuatara, Sphenodon punctatus). Biological Conservation 135, 181-188.

Moore, J. A., Nelson, N. J., Keall, S. N. and Daugherty, C. H. (2008). Implications of social dominance and multiple paternity for the genetic diversity of a captive-bred reptile population (tuatara). Conservation Genetics 9, 1243-1251.

Mooring, M. S. and Hart, B. L. (1997). Self grooming in impala mothers and lambs: testing the body size and tick challenge principles. Animal Behaviour 53, 925-934.

Murray, D. L. (2002). Differential body condition and vulnerability to predation in snowshoe hares. Fournal of Animal Ecology 71, 614-625.

Navarro, C., Marzal, A., De Lope, F. and Moller, A. P. (2003). Dynamics of an immune response in house sparrows Passer domesticus in relation to time of day, body condition and blood parasite infection. Oikos 101, 291-298.

Needham, G. R. and Teel, P. D. (1991). Off-host physiological ecology of ixodid ticks. Annual Review of Entomology 36, 659-681.

Neiffer, D. L., Lydick, D. L., Burks, K. and Doherty, D. (2005). Hematologic and plasma biochemical changes associated with fenbendazole administration in Hermann's tortoises (Testudo hermanni). Fournal of Zoo and Wildlife Medicine 36, 661-672.

Nelson, N. J., Keall, S. N., Brown, D. and Daugherty, C. H. (2002). Establishing a new wild population of tuatara (Sphenodon guntheri). Conservation Biology 16, 887-894.

Neuhaus, P. (2003). Parasite removal and its impact on litter size and body condition in Columbian ground squirrels (Spermophilus columbianus). Proceedings of the Royal Society of London, B, 270 (Suppl.) S213-S215.

Oliver, J. H. (1989). Biology and systematics of ticks (Acari:Ixodida). Annual Review of Ecology and Systematics 20, 397-430.

Platenberg, R. J. and Griffiths, R. A. (1999). Translocation of slow-worms (Anguis fragilis) as a mitigation strategy: a case study from south-east England. Biological Conservation 90, 125-132. 
Püttker, T., Meyer-Lucht, Y. and Sommer, S. (2008). Effects of fragmentation on parasite burden (nematodes) of generalist and specialist small mammal species in secondary forest fragments of the coastal Atlantic Forest, Brazil. Ecological Research 23, 207-215.

R Core Development Team (2007). $R$ : A Language and Environment for Statistical Computing. Vienna, Austria. http://www.R-project.org

Robb, L. A., Martin, K. and Hannon, S. J. (1992). Spring body condition, fecundity and survival in female willow ptarmigan. Fournal of Animal Ecology 61, 215-223.

Roberts, M. L., Buchanan, K. L. and Evans, M. R. (2004). Testing the immunocompetence handicap hypothesis: a review of the evidence. Animal Behaviour 68, 227-239.

Ruffell, J. (2005). The use of translocation as a tool in tuatara (Sphenodon spp.) conservation and relationships between the tuatara and the tick Aponomma sphenodonti. M.Sc. Thesis, University of Auckland, Auckland, New Zealand.

Sasa, M. (1961). Biology of chiggers. Annual Review of Entomology 6, 221-244.

Schulte-Hostedde, A. I., Zinner, B., Millar, J. S. and Hickling, G. J. (2005). Restitution of mass-size residuals: validating body condition indices. Ecology $\mathbf{8 6}$, 155-163.

Smith, K. F., Acevedo-Whitehouse, K. and Pedersen, A. B. (2009). The role of infectious diseases in biological conservation. Animal Conservation 12, $1-12$.

Spratt, D. M. (1997). Endoparasite control strategies: implications for biodiversity of native fauna. International fournal for Parasitology 27, 173-180.

Stevenson, R. D. and Woods, W. A., Jr. (2006). Condition indices for conservation: new uses for evolving tools. Integrative and Comparative Biology 46, 1169-1190.
Szél1, Z., Sréter, T. and Varga, I. (2001). Ivermectin toxicosis in a chameleon (Chamaeleo senegalensis) infected with Foleyella furcata. Fournal of Zoo and Wildlife Medicine 32, 115-117.

Thompson, J. N. (1996). Evolutionary ecology and the conservation of biodiversity. Trends in Ecology and Evolution 11, 300-303.

Tomas, G., Merino, S., Moreno, J. and Morales, J. (2007). Consequences of nest reuse for parasite burden and female health and condition in blue tits, Cyanistes caeruleus. Animal Behaviour 73, 805-814.

Ujvari, B. and Madsen, T. (2005). Age, parasites, and condition affect humoral immune response in tropical pythons. Behavioral Ecology 17, 20-24.

Valera, F., Hoi, H. and Kristin, A. (2006). Parasite pressure and its effects on blood parameters in a stable and dense population of the endangered Lesser grey shrike. Biodiversity and Conservation 15, 2187-2195.

Walls, G. Y. (1981). Feeding ecology of the tuatara Sphenodon punctatus on Stephens Island, Cook Strait. New Zealand Fournal of Zoology 4, 89-97.

Walls, G. Y. (1983). Activity of the tuatara and its relationships to weather conditions on Stephens Island, Cook Strait, with observations on geckos and invertebrates. New Zealand Fournal of Zoology 10, 309-318.

Wauters, L. A., Vermeulen, M., Van Dongen, S., Bertolino, S., Molinari, A., Tosi, G. and Matthysen, E. (2007). Effects of spatio-temporal variation in food supply on red squirrel Sciurus vulgaris body size and body mass and its consequences for some fitness components. Ecography 30, 51-65.

Wharton, G. W. (1952). A Manual of the Chiggers. Entomological Society of Washington, Washington DC, USA.

Zhang, J. S., Daszak, P., Huang, H. L., Yang, G. Y., Kilpatrick, A. M. and Zhang, S. (2008). Parasite threat to panda conservation. Ecohealth 5, 6-9. 